Article

\title{
Green Transport Balanced Scorecard Model with Analytic Network Process Support
}

\author{
David Staš $^{\dagger}$, Radim Lenort ${ }^{\dagger}, *$, Pavel Wicher ${ }^{\dagger}$ and David Holman ${ }^{\dagger}$ \\ Department of Logistics and Quality Management, ŠKODA AUTO University, Na Karmeli 1457, \\ Mladá Boleslav 293 01, Czech Republic; E-Mails: david.stas@savs.cz (D.S.); \\ pavel.wicher@savs.cz (P.W.); david.holman@savs.cz (D.H.) \\ $\dagger$ These authors contributed equally to this work. \\ * Author to whom correspondence should be addressed; E-Mail: radim.lenort@savs.cz; \\ Tel.: +420-597-325-159.
}

Academic Editors: Russell G. Thompson and Benjamin T. Hazen

Received: 8 September 2015 / Accepted: 6 November 2015 / Published: 18 November 2015

\begin{abstract}
In recent decades, the performance of economic and non-economic activities has required them to be friendly with the environment. Transport is one of the areas having considerable potential within the scope. The main assumption to achieve ambitious green goals is an effective green transport evaluation system. However, these systems are researched from the industrial company and supply chain perspective only sporadically. The aim of the paper is to design a conceptual framework for creating the Green Transport (GT) Balanced Scorecard (BSC) models from the viewpoint of industrial companies and supply chains using an appropriate multi-criteria decision making method. The models should allow green transport performance evaluation and support of an effective implementation of green transport strategies. Since performance measures used in Balanced Scorecard models are interdependent, the Analytic Network Process (ANP) was used as the appropriate multi-criteria decision making method. The verification of the designed conceptual framework was performed on a real supply chain of the European automotive industry.
\end{abstract}

Keywords: green transport; balanced scorecard; analytic network process; automotive industry 


\section{Introduction}

In recent decades, the performance of economic and non-economic activities has required them to be friendly to the environment. Transport is one of the areas with considerable potential within the scope since it has significant negative impacts on the environment. This proactive approach to addressing and eliminating the negative environmental impacts from company and supply chain transport processes is called Green Transport (GT).

The current goals of GT are focused on reducing the fuel consumption (which is closely linked to cutting $\mathrm{CO}_{2}$ and other exhaust gases), reducing noise, reducing the transport costs, reducing traffic jams and, ultimately, on complying with the legislative restrictions. An active and effective solution of the issues of GT must be seen not only as a challenge, but especially as an opportunity offering the possibility of significant competitive advantage, improving the image of the company in the eyes of the customers, region, state and the general public.

The main assumption to achieve these ambitious goals is an effective green transport evaluation system, which allows not only measurement, monitoring, and evaluation of GT performance but also supporting green transport strategies in industrial companies and supply chains.

However, on the basis of a detailed literature review in the area of the GT evaluation systems, it can be stated that:

(1) GT evaluation systems are a worldwide processed described and developed topic but only from a multinational and national perspective, especially for the area of urban or public transport (see e.g., [1-4]).

(2) GT evaluation systems are usually included in a broader concept of sustainable transport, which, apart from the environmental aspects, also deals with the economic and social criteria [5-8].

(3) GT fields from the viewpoint of industrial companies or supply chains in the available GT evaluation systems are addressed only sporadically and marginally (see e.g., [9]).

(4) There is no available GT evaluation system for industrial companies or supply chains based on Balanced Scorecard model. Sporadically, Green Supply Chain Balanced Scorecard models were proposed $[10,11]$.

(5) As a result of different importance of green performance measures, GT evaluation systems should be based on multi-criteria decision making methods $[10,12,13]$.

The aim of the paper is to design a conceptual framework for creating the Green Transport Balanced Scorecard models from the viewpoint of industrial companies and supply chains using an appropriate multi-criteria decision making method. The models should allow GT performance evaluation and support of an effective implementation of GT strategies. Since performance measures used in Balanced Scorecard models are interdependent [14], multi-criteria decision making methods that do not require independence among measures must be used. The Analytic Network Process meets this requirement [15]. The article is based on authors' considerations first published in the CSCC'2015 conference paper [16]. 


\section{Experimental Section}

The experimental section contains the methodological base of the designed conceptual framework, the conceptual framework design, and the case study, which was used for the verification of the framework.

\subsection{Methodological Base}

Balanced Scorecard and Analytic Network Process were used as the main methodological approaches for the conceptual framework design.

\subsubsection{Balanced Scorecard}

Balanced Scorecard (BSC) is a method of management that creates a link between strategy and operational activities with an emphasis on performance measurement [14]. The BSC model (see Figure 1) was first introduced in 1992 by Kaplan and Norton, and has since then become a widely adopted approach to management control and performance management by both business and government. The BSC was created as a complement to financial measures, not as a substitute [17], and worked on balancing the four perspectives in order to give a comprehensive description of the business.

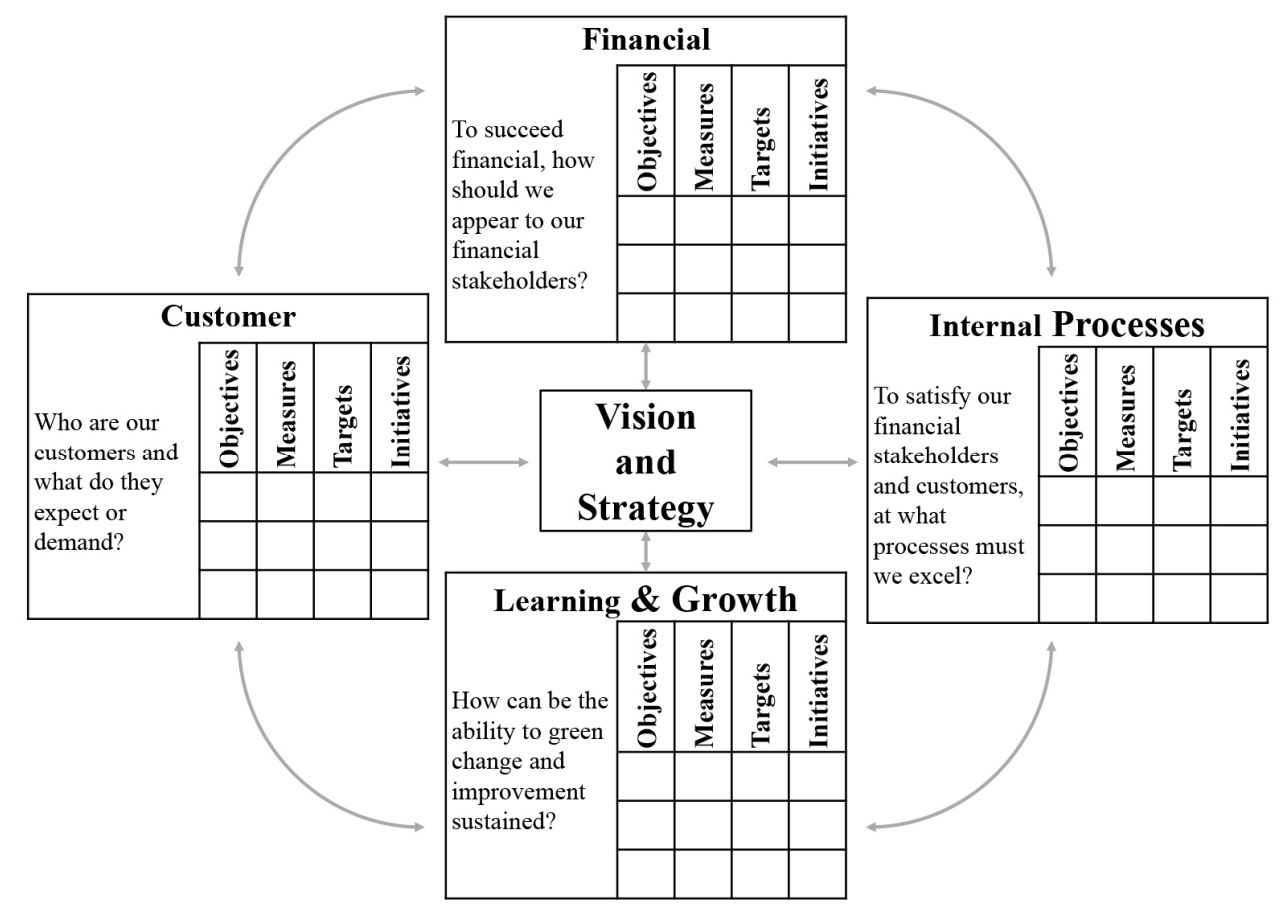

Figure 1. The Balanced Scorecard model [14].

By using the BSC, the strategy and vision of the company can be converted into performance measures that include both outcome measures and the drivers of these measures $[17,18]$. For a strategy to be successful, it needs to consider financial ambitions, processes to be improved, markets served and the people in the organization that implement the strategy [19]. The BSC uses all these perspectives by considering both internal and external aspects [20]. Every perspective should contain four different sections: objectives, measures, targets and initiatives. For employees to be able to act 
upon the organization's vision, translating the strategy and mission of the company into objectives is the first step in the creation of each perspective.

Strategies like "an empowered organization" are hard to implement in practice and senior executives should therefore create understandable and actionable objectives, along with defined measures to keep track of the progress of reaching each goal [21]. Each measure should then be associated with a target (a short-term goal) that works as a milestone to assist in evaluating the progress of each objective. The last column in each perspective should be initiatives, describing actions that should be undertaken by the firm to reach each objective.

\subsubsection{Analytic Network Process}

The Analytic Network Process (ANP) is a multistage decomposition method used to solve decision-making problems involving more than one criterion of optimality developed by Saaty [15]. The basic idea is to create a decision-making network and the subsequent evaluation of importance of the single links among the interconnected elements. These evaluations are represented by weights, which are determined on the basis of pair comparison. The ANP does not limit human understanding and experience to force decision-making into a highly technical model that is unnatural and contrived. It is in essence a formalization of how people usually think, and it helps the decision-maker keep track of the process as the complexity of the problem and the diversity of its factors increase [22].

ANP is based on the implementation of three basic steps (modified according to $[15,23,24]$ ):

(1) Model construction.

A decision-making problem is analysed by researchers and transformed into the network structure. This network contains elements/nodes, clusters and connections. The elements symbolise fundamental building blocks of the network. They represent both criteria and alternatives. Clusters are groupings of elements, which are logically related factors of the decision. Connections determine dependences among elements. The elements can affect and can be affected by other elements in their cluster (inner dependence) or in the whole network (outer dependence).

(2) Pairwise comparison matrices and priority vectors.

The determination of weights is based on node pairwise comparisons when one element depends on two or more different elements from one cluster and on cluster pairwise comparisons when elements (one or more) from one cluster depend on two or more elements from other clusters. The relative importance values are determined with Saaty's 1-9 scale presented in Table 1.

Table 1. The fundamental scales of pairwise comparison [15].

\begin{tabular}{cc}
\hline Intensity of Importance & Definition \\
\hline 1 & Equal importance \\
3 & Moderate importance \\
5 & Strong importance \\
7 & Very strong importance \\
9 & Absolute importance \\
$2,4,6,8$ & Intermediate values \\
\hline
\end{tabular}


Pairwise comparisons are performed in the framework of node and cluster matrices, and local priority vectors are derived as estimates of the relative importance associated with the elements or clusters being compared.

(3) Supermatrix construction.

In the first step, the unweighted supermatrix is created directly from all local priority vectors. In the second step, the weighted supermatrix is calculated by multiplying the values of the unweighted supermatrix with their affiliated cluster weights. By normalizing the weighted supermatrix, it is made column stochastic. In the third and final step, the limit supermatrix is processed by raising the entire supermatrix to powers until it converges in terms of lines. Limit priority values within this supermatrix indicate the flow of influence of an individual element towards the overall goal. Since the decision alternatives are elements of an original cluster of the network, their limit priorities are synonymous with their contributions to the goal and are used for the ranking of alternatives, being normalized within the cluster [25].

\subsection{Conceptual Framework Design}

Designed conceptual framework includes the selection of green transport strategy, selection of Balanced Scorecard approach, specification of green transport strategy, prioritization of Balanced Scorecard measures, and evaluation of green transport strategy reaching (see Figure 2).

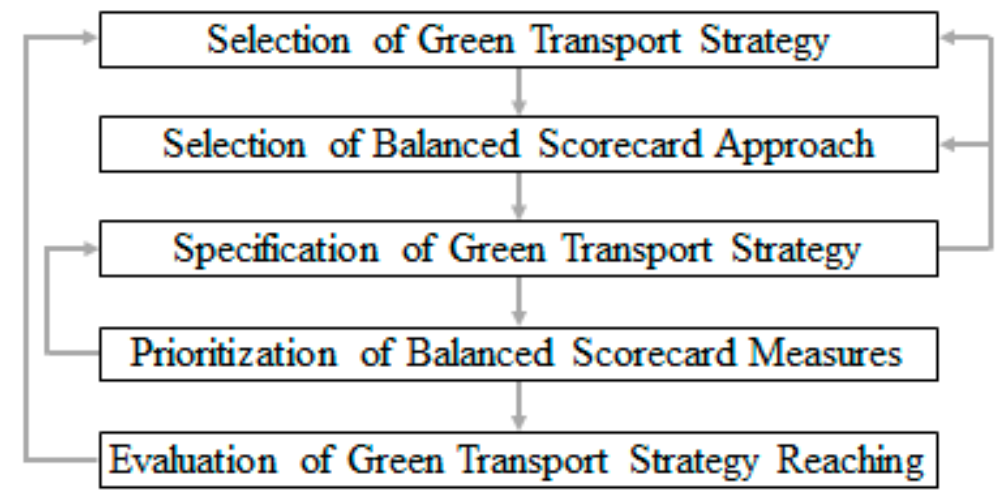

Figure 2. Designed conceptual framework.

Practical application of the designed conceptual framework will only rarely have the presented "linear" form and will not be realized in such a transparent and clear manner. It will be necessary to take into account the following facts:

- The creation of the Green Transport Balanced Scorecard models will be an iterative process with returns to previously adopted and re-evaluated procedures (see feedbacks in Figure 2). The first possible feedbacks are in the step Specification of Green Transport Strategy. During this step, a need for selection of a different BSC approach (step 2) or even GT strategy (step 1) can appear. The next possible feedback is in the step Prioritization of Balanced Scorecard Measures where the results of the prioritization can lead to changes in the specification of GT Strategy (step 3). The final possible feedback is in the step Evaluation of GT strategy reaching. After the 
evaluation, it can be stated that the selected GT strategy was too challenging or not challenging enough (step 1). If some step is changed, all of the next steps must be carried out again.

- The partial steps in the designed framework will often be interrelated (e.g., Specification of GT strategy can be conducted simultaneously with the Prioritization of Balanced Scorecard measures).

- Thanks to its strategic importance, the creation of the Green Transport Balanced Scorecard models will be a nonstandard, original and creative process, which does not exclude the use of partial formal methods and tools making the thought processes easier.

- The creation of the Green Transport Balanced Scorecard models will be a process of continuous adaptation to changes in the internal and external environment, which are continuous as well.

\subsubsection{Selection of Green Transport Strategy}

The key step of the conceptual framework is the selection of an appropriate green transport strategy. For that purpose, authors of the paper offer GT strategy matrix, which is shown in Figure 3.

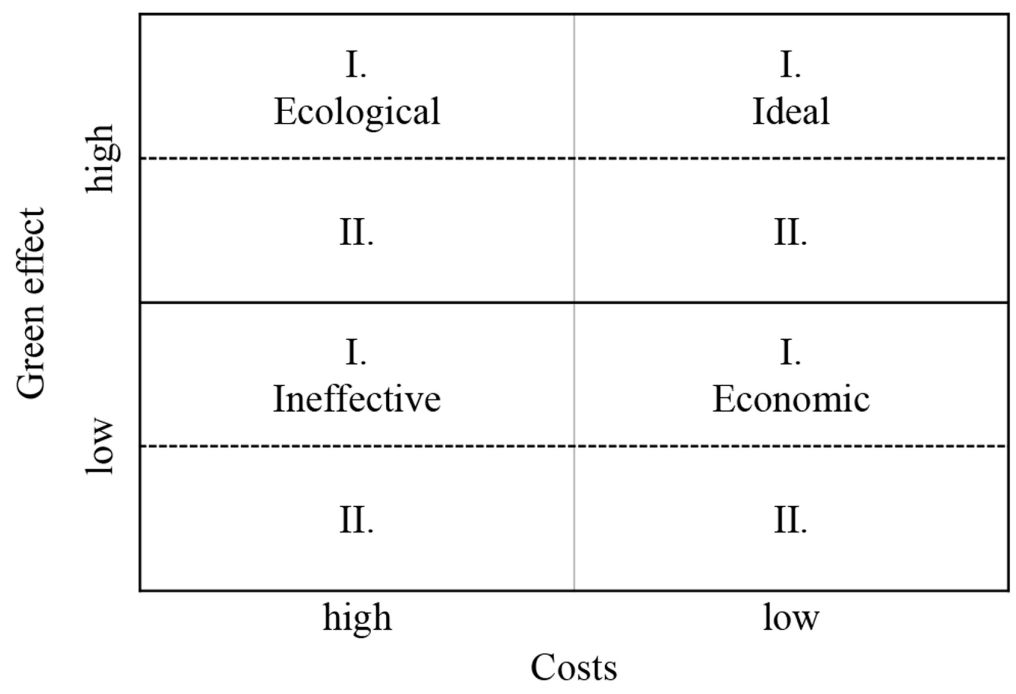

Figure 3. Green transport strategy matrix.

The GT strategy matrix is based on the following criteria:

(1) Expected green effect after the GT strategy implementation-low or high.

(2) Estimated cost of the GT strategy implementation-low or high.

(3) Responsibility to decide on the GT strategy implementation in the given company: (I) In the responsibility of the implementers or (II) Limited responsibility of the implementers (e.g., within the responsibility of another company department or corporation).

The results are four main GT strategies:

(1) Ideal-high green effect can be achieved at low costs or even cost savings.

(2) Economic - only a limited green effect can be achieved at low costs or even cost savings.

(3) Ecological — incurring high costs will achieve a high green effect.

(4) Ineffective-incurring high costs brings only a limited green effect. 
The ideal GT strategy is generally used in companies and supply chains, which start with green politics. Economic and Ecological GT strategies are implemented when the Ideal strategy is depleted. Ineffective GT strategy should not be used at all. At the same time, green initiatives within the direct responsibility of the implementers are preferred in frame of the selected main GT strategy.

In practice, the selection of GT strategy depends on specific conditions in the researched company, especially on the company and/or corporation strategy. Thus, the values "low" and "high" are determined by company and/or corporation top managers. From the authors' experience can be stated that the threshold between low and high green effects are done by green strategic goals of the company top management or corporation. The larger are stakeholders' expectations, the more challenging will be green strategy goals and the higher will be the threshold value. In case of the costs, threshold value means zero additional investments in comparison with the accepted company business plan.

\subsubsection{Selection of Balanced Scorecard Approach}

According to Butler et al. [26], options for incorporating sustainability/green into the BSC include:

(1) Adding a fifth perspective to the BSC.

(2) Developing a separate sustainable/green BSC.

(3) Integrating the measures throughout the four perspectives.

Adding a fifth perspective to the BSC may be the simplest approach. For example, Kurien and Qureshi propose the Environment perspective with three indexes: environment, social, and economic [10]. It could provide more visibility but not necessarily increased importance to the green ability aspects of corporate management. Isolating green measures in a separate perspective might weaken environmental initiatives by not providing clear ties to the other perspectives and to corporate strategies.

The strength of developing a separate green BSC is the fact that a green BSC can be used to implement a green strategy [27]. However, the free-standing nature may fail to help the company tie environmental aspects directly into the corporate strategy. There are two possibilities:

(1) To use the four original perspectives with completely new green measures (see e.g., [28]).

(2) To develop new green perspectives. For instance, Hsu et al. propose perspectives as follows: sustainability, stakeholders, internal business processes, and learning and growth [29].

Integrating new measures throughout the existing four perspectives has the advantage of allowing the measures to be seen as fundamental to day-to-day operations. Integration indicates that management recognizes there are cause and effect linkages between corporate strategies and green efforts.

The authors of the paper suggest the use of the second approach with four original perspectives for GT strategy implementation on the company/supply chain transport level and the third approach for company/supply chain level. However, it is only a recommendation, and the final selected approach will depend on a particular situation in an analysed company/supply chain.

Green Transport Balanced Scorecard (GTBSC) model shown in Figure 4 was designed for strategy implementation on the company/supply chain transport level.

There are two basic differences in comparison with traditional BSC model (compare Figures 1 and 4): 
(1) Only green measures are taken into consideration.

(2) In addition to target values, there are threshold and real values. Thresholds represent minimum accepted values of the measures. Realities describe real values of the measures.

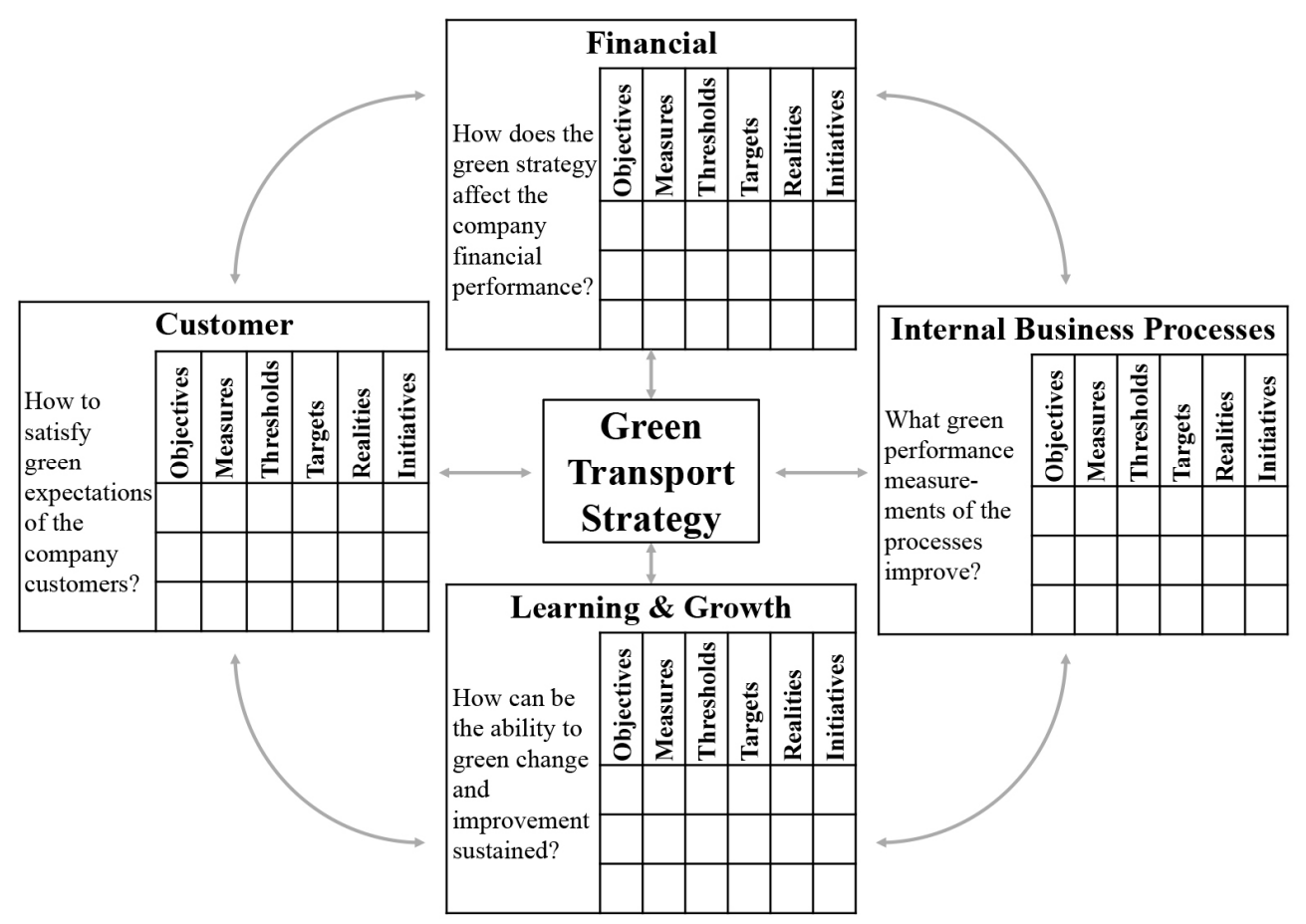

Figure 4. Green Transport Balanced Scorecard model.

\subsubsection{Specification of Green Transport Strategy}

Specific green objectives, measures, thresholds, targets, and initiatives are determined in this step according to the selected GT strategy and the contemporary green transport performance in the given company/supply chain. The authors of the paper designed the conceptual framework for assessing the green transport performance in industrial companies and supply chains for that purpose [30].

The framework contains 30 general green best practices/initiatives (see Table 2), which are divided into four areas:

(1) Strategy - practices creating the basis of a successful application of other best practices or they have the character of supply chain structural changes.

(2) Management - practices focused on planning and subsequent execution of transport.

(3) Technology-technical innovations of the means of transport, equipment, ICT systems and packages.

(4) Staff-practices whose motive power is represented by the people and their skills.

The green best practices/initiatives were created on the basis of a detailed reference sources review. More than 170 best practices have been analysed altogether. The principal sources of information were [31-36]. 
Table 2. Green best practices/initiatives.

\begin{tabular}{|c|c|c|}
\hline Field & No. & Best Practices/Initiatives \\
\hline \multirow{6}{*}{ Strategy } & 1 & Small distance of the key suppliers \\
\hline & 2 & Eco-efficient network optimization \\
\hline & 3 & Centralisation of production plants \\
\hline & 4 & Efficient system of monitoring indicators of Green transport \\
\hline & 5 & Green partnership platform with all stakeholders \\
\hline & 6 & Logistics service providers with implemented Green politics \\
\hline \multirow{6}{*}{ Management } & 7 & Utilisation of fully-loaded direct supplies and milk runs \\
\hline & 8 & Utilisation of the intermodal transport \\
\hline & 9 & Suppliers agreement for sharing their warehouses \\
\hline & 10 & Collaborative delivery planning with your suppliers/customers \\
\hline & 11 & Cooperation in transport utilization with logistics service providers \\
\hline & 12 & Utilisation of back rides \\
\hline \multirow{13}{*}{ Technology } & 13 & Sophisticated ICT for transport planning and control \\
\hline & 14 & High transport capacity utilization \\
\hline & 15 & Utilisation of alternative fuels and engines \\
\hline & 16 & Innovated fleet \\
\hline & 17 & Sophisticated software for route optimization \\
\hline & 18 & Utilisation of road trains \\
\hline & 19 & Utilisation of double deck vehicles and other two-level systems \\
\hline & 20 & Utilisation of one-way pallets or other packages for long transports \\
\hline & 21 & Minimizing the loading/unloading time \\
\hline & 22 & Utilisation of telematics systems for efficient transport operations \\
\hline & 23 & Careful preventive maintenance of fleet \\
\hline & 24 & Light vehicles \\
\hline & 25 & Utilisation of engine shutdown during waiting times \\
\hline \multirow{5}{*}{ Staff } & 26 & Eco-efficient motivation system for drivers \\
\hline & 27 & Eco-efficient motivation system for company logistics staff \\
\hline & 28 & Green training of drivers \\
\hline & 29 & Green training of company logistics staff \\
\hline & 30 & Eco-efficient new drivers selection \\
\hline
\end{tabular}

During the specification of the green objectives, measures, thresholds, targets, and mainly initiatives, it can be obvious that the BSC approach selected before can not be used or the chosen GT strategy can't even be achieved. In this case, it is necessary to return to these steps and change the previously adopted decisions.

\subsubsection{Prioritization of Balanced Scorecard Measures}

The task of this step is the creation of a system for measurement of reaching the selected GT strategy. It is based on the assignment of weights of the four perspectives and their measures. The authors of the paper suggest the ANP method for that purpose because there are significant dependences between the perspectives and also their measures. 
Measures with the highest weight should be incorporated to the existing company/supply chain BSC model to ensure the unity between the company/supply chain strategy and the GT strategy.

During this step, it can be stated that some measures have such small significance that it is possible to remove or replace them (which leads to return to the Specification of GT Strategy).

\subsubsection{Evaluation of Green Transport Strategy Reaching}

Real values of the selected measures are collected during this step. Using the ANP method, performance of the selected GT strategy reaching can be calculated. The evaluation of the results may include:

(1) Comparison of the calculated value with the overall threshold and target values.

(2) Inclusion of the calculated value into the pre-defined categories (unacceptable, bad, good, very good, excellent GT strategy reaching).

(3) Analysis of the trend if the evaluation of the GT strategy reaching is performed repeatedly.

If there is an unsatisfactory GTS reaching, it is desirable to focus on the perspectives and measures with the highest weight.

After the evaluation, it can be stated that the selected GT strategy was too challenging or not challenging enough, and it is suitable to return to step 1.

\subsection{Case Study}

The verification of the designed conceptual framework is performed on a real supply chain of the European automotive industry. The GT strategy implementing took place in a company, which is incorporated in a multinational corporation. The framework was implemented by the GT strategy project team, which included the logistics director (to assure consensus between GT strategy and the company strategy), the green project manager (a person responsible for GT strategy implementation), logistics managers/experts from transport area and the authors of the framework (academics). Given the sensitivity of the used data, this section presents only an illustrative case study.

\subsubsection{Selection of Green Transport Strategy}

GT strategy is related to inbound, internal, and outbound transport, which is planned and controlled by the company. The Ideal GT strategy is used in this case study, because top management of the company has set the challenging green goal: to reduce emissions per unit produced by $8 \%$ in a three year strategic horizon (high green effect). On the contrary, the top management prefers that such green projects, which are profitable, eventually have a minimum loss (low costs).

\subsubsection{Selection of Balanced Scorecard Approach}

As the GT strategy is only a partial strategy of the company (Company strategy $\rightarrow$ Green strategy $\rightarrow$ Green logistics strategy $\rightarrow$ GT strategy), the designed GTBSC appears as an appropriate tool for GT strategy implementation. 


\subsubsection{Specification of Green Transport Strategy}

Specific green objectives, measures, threshold, target and real values, and initiatives for each perspective are summed up in Table 3. Evaluation of reaching the objectives and their measures is carried out on an annual basis. Threshold, target and real values of the measures F1, P1, L1, L2, and $\mathrm{C} 2$ are expressed as annual change in percentages. Only objectives and initiatives related to the Ideal GT strategy in the responsibility of the company were selected.

Table 3. Specification of the selected green transport (GT) strategy.

\begin{tabular}{|c|c|c|c|c|c|c|c|}
\hline Perspectives & Objectives & Measures & Units & Thresholds & Targets & Realities & Initiatives \\
\hline \multirow[b]{2}{*}{ Financial } & Transport cost saving & $\begin{array}{l}\text { F1: Transport } \\
\text { costs/Produced cars }\end{array}$ & EUR/car & $1 \%$ & $3 \%$ & $2.5 \%$ & \multirow{3}{*}{$\begin{array}{l}\text { 4-Efficient system of } \\
\text { green transport } \\
\text { monitoring indicators }\end{array}$} \\
\hline & $\begin{array}{l}\text { High return on } \\
\text { investments in green } \\
\text { projects } \\
\end{array}$ & $\begin{array}{l}\text { F2: (Net project benefits/Project } \\
\text { costs) } \times 100\end{array}$ & $\%$ & 0 & 20 & 5 & \\
\hline $\begin{array}{l}\text { Internal } \\
\text { Business } \\
\text { Processes } \\
\end{array}$ & $\begin{array}{l}\text { Decreasing the } \\
\mathrm{CO}_{2} \text { emissions }\end{array}$ & P1: $\mathrm{CO}_{2}$ emissions/Produced cars & $\mathrm{g} / \mathrm{car}$ & $1 \%$ & $3 \%$ & $4 \%$ & \\
\hline \multirow{2}{*}{$\begin{array}{l}\text { Learning and } \\
\text { Growth }\end{array}$} & $\begin{array}{l}\text { Increasing the } \\
\text { green knowledge }\end{array}$ & $\begin{array}{l}\text { L1: Green training hours/ } \\
\text { Number of logistics staff }\end{array}$ & $\begin{array}{l}\text { hours/ } \\
\text { person }\end{array}$ & $25 \%$ & $50 \%$ & $30 \%$ & $\begin{array}{l}\text { 14-High transport } \\
\text { capacity utilisation }\end{array}$ \\
\hline & $\begin{array}{l}\text { Increasing the green } \\
\text { innovativeness of } \\
\text { logistics staff }\end{array}$ & $\begin{array}{l}\text { L2: Number of successful green } \\
\text { innovations/Number of } \\
\text { logistics staff }\end{array}$ & pes/ & $0 \%$ & $30 \%$ & $25 \%$ & \multirow{3}{*}{$\begin{array}{l}\text { 27-Eco-efficient } \\
\text { motivation system } \\
\text { for company } \\
\text { logistics staff }\end{array}$} \\
\hline \multirow[b]{2}{*}{ Customer } & $\begin{array}{l}\text { Increasing the green } \\
\text { image of transport }\end{array}$ & $\begin{array}{l}\text { C1: Number of positive } \\
\text { evaluation in a survey }\end{array}$ & $\%$ & 60 & 90 & 75 & \\
\hline & $\begin{array}{l}\text { Reducing the local } \\
\text { environmental impacts }\end{array}$ & $\begin{array}{l}\text { C2: Number of arriving } \\
\text { and departing } \\
\text { trucks/Produced cars }\end{array}$ & $\mathrm{pcs} / \mathrm{car}$ & $1 \%$ & $4 \%$ & $3 \%$ & \\
\hline
\end{tabular}

The first main top management requirement, a high green effect, is taken into the consideration through the internal business perspective. The objective was defined as decreasing the $\mathrm{CO}_{2}$ emissions because $\mathrm{CO}_{2}$ is considered as the most important part of greenhouse gas emissions by the corporation. The company has growth strategy, which is based on increasing the number of produced cars in the next few years. It means also increasing the absolute value of the $\mathrm{CO}_{2}$ emissions. For that reason, the objective is measured per produced car (F1). The measure uses gram per car as the unit. Threshold, target and real values of the measure are expressed as annual change in percentages. The threshold value ensures a minimum accepted emission decreasing. There is a minimum $1 \%$ decrease in the company pessimistic scenario. The three-year strategic goal in emissions decreasing by $8 \%$ fits to annual $3 \%$ rate of the $\mathrm{CO}_{2}$ emissions decreasing. The real value represents the annual $\mathrm{CO}_{2}$ emissions decreasing between years 2013 and 2014.

The second requirement related to low costs approach is expressed by a financial perspective. The company top management prefers such green projects, which are profitable. For that reason, the objective high return on investments in green project was defined. The standard measure, which is used in the company for evaluation of projects' profitability, is the share of net profit benefits (project 
benefits minus project costs) and project costs. For that reason, the same formula was used as the measure of the objective (F2). Unit of the measure is percentage. The threshold value says that green project costs must be minimally equal to its benefits. The target value shows that these projects should have $20 \%$ of the profitability. The real value represents the average profitability of all green projects in 2014.

The learning and growth and the customers perspectives support the ones mentioned above.

Similarly, only such initiatives that represent systematic and sustainable emission decreasing (high green effect) and do not require high investments (low costs approach) were selected.

\subsubsection{Prioritization of Balanced Scorecard Measures}

A network structure, which expresses dependences among the goal/green transport strategy, clusters/perspectives and nodes/measures is shown in Figure 5. The orientation of the arrows determines the type of dependencies. The green transport strategy depends on all perspectives and measures. There are also interdependencies among the measures from the other perspectives. Only the main ones were taken into consideration (see Table 4).

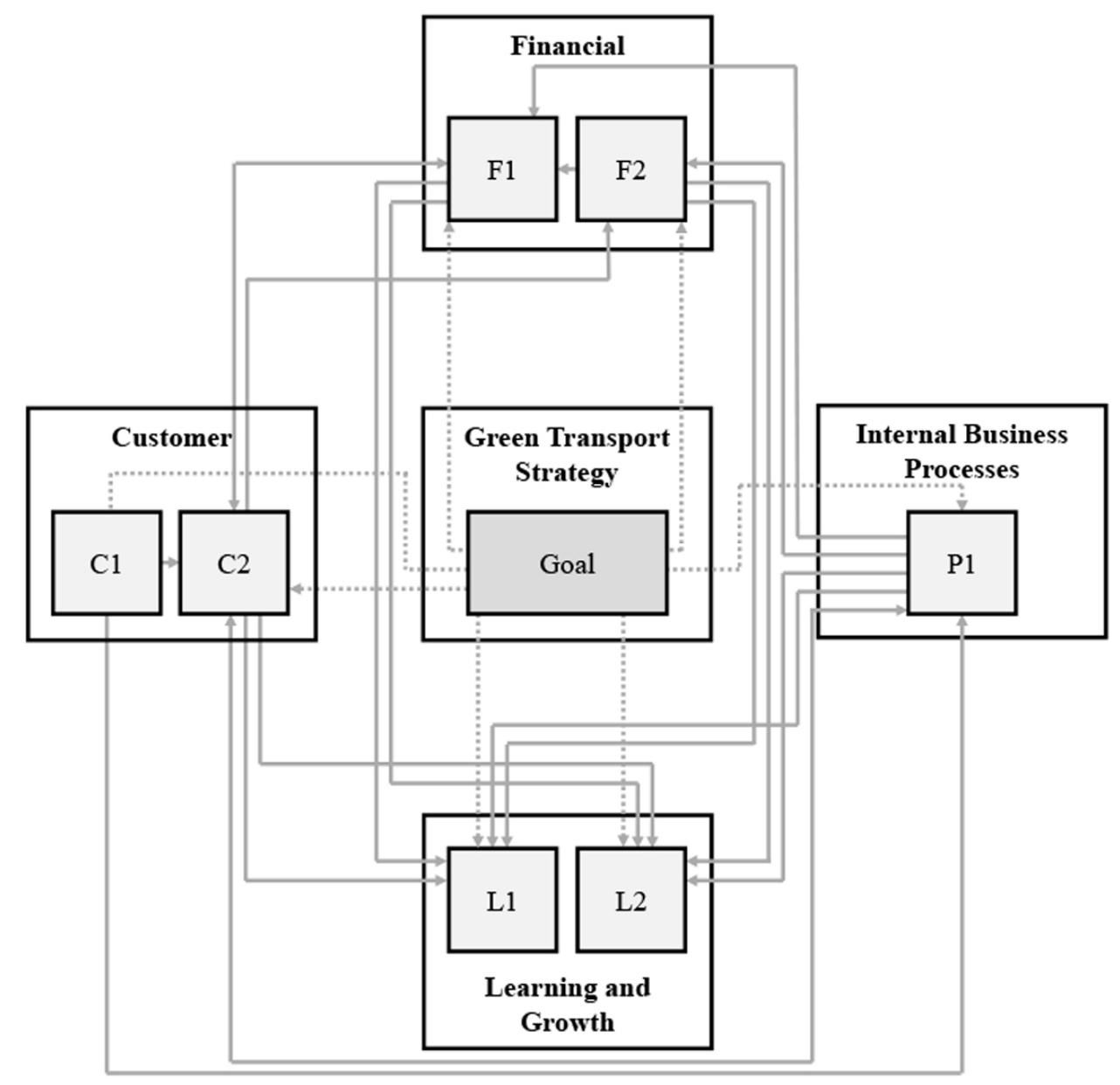

Figure 5. Network structure of the designed GTBSC model. 
Table 4. Measures' interdependencies.

\begin{tabular}{|c|c|c|}
\hline Measure & Depends on & Explanation \\
\hline \multirow{3}{*}{ F1 } & L1 & Increasing the green knowledge usually means transport cost saving \\
\hline & $\mathrm{L} 2$ & Increasing the green innovativeness of logistics staff usually means transport cost saving \\
\hline & $\mathrm{C} 2$ & Decreasing the number of arriving and departing trucks means transport cost saving \\
\hline \multirow{3}{*}{$\mathbf{F 2}$} & F1 & $\begin{array}{l}\text { Transport cost saving means increasing the net green project benefits and the return on investments in } \\
\text { green projects }\end{array}$ \\
\hline & L1 & Increasing the green knowledge usually means increasing the return on investments in green projects \\
\hline & $\mathrm{L} 2$ & $\begin{array}{l}\text { Increasing the green innovativeness of logistics staff usually means increasing the return on investments in } \\
\text { green projects }\end{array}$ \\
\hline \multirow{5}{*}{ P1 } & F1 & $\begin{array}{l}\text { Transport cost saving is usually based on decreasing of kilometres travelled, which means decreasing the } \\
\mathrm{CO}_{2} \text { emissions }\end{array}$ \\
\hline & $\mathrm{F} 2$ & The main goal of any green project is to decrease the $\mathrm{CO}_{2}$ emissions \\
\hline & L1 & Increasing the green knowledge is primarily oriented on decreasing the $\mathrm{CO}_{2}$ emissions \\
\hline & $\mathrm{L} 2$ & Increasing the green innovativeness of logistics staff is primarily oriented on decreasing the $\mathrm{CO}_{2}$ emissions \\
\hline & $\mathrm{C} 2$ & Decreasing the number of arriving and departing trucks means decreasing the $\mathrm{CO}_{2}$ emissions \\
\hline \multirow{2}{*}{ C1 } & $\mathrm{P} 1$ & Decreasing the $\mathrm{CO}_{2}$ emissions is important information for some groups of customers \\
\hline & $\mathrm{C} 2$ & Reducing the local environmental impacts means increasing the green image of transport \\
\hline \multirow{5}{*}{$\mathbf{C 2}$} & F1 & $\begin{array}{l}\text { Transport cost saving is usually based on decreasing the kilometres travelled, which means decreasing the } \\
\text { number of arriving and departing trucks }\end{array}$ \\
\hline & $\mathrm{F} 2$ & The main goal of most green projects is decreasing the local environmental impacts \\
\hline & P1 & $\begin{array}{l}\text { Effort for decreasing the } \mathrm{CO}_{2} \text { emissions usually means decreasing the number of arriving and departing } \\
\text { trucks (assuming the Ideal GT strategy) }\end{array}$ \\
\hline & L1 & Increasing the green knowledge usually means reducing the local environmental impacts \\
\hline & $\mathrm{L} 2$ & $\begin{array}{l}\text { Increasing the green innovativeness of logistics staff usually means reducing the local } \\
\text { environmental impacts }\end{array}$ \\
\hline
\end{tabular}

SuperDecisions software was used for the application of the ANP method. The software was written by the ANP Team working for the Creative Decisions Foundation. There are subnets at each measure, which are used for assignment of the threshold, target and real values.

To obtain global weights of all measures, cluster and node pairwise comparisons (given by the perspective and measures interdependencies) must be conducted. The cluster pairwise comparison matrices are shown in Tables 5 and 6, the node pairwise comparison matrices in Tables 7 and 8 . From these tables, it is obvious that the differences in intensity of importance are relatively low. It is caused by the fact that all selected measures belong to the key (the most significant) indicators. There are no medium or less significant measures where these differences would be stronger. A similar situation is related to perspectives. The nature of the BSC is based on a balanced selection of perspectives.

Table 5. Cluster pairwise comparison with respect to Green Transport Strategy.

\begin{tabular}{ccccc}
\hline Clusters & Financial & Internal Business Processes & Learning and Growth & Customer \\
\hline Financial & $\mathrm{x}$ & 2 & 3 & 2 \\
Internal Business Processes & $1 / 2$ & $\mathrm{x}$ & 2 & 1 \\
Learning and Growth & $1 / 3$ & $1 / 2$ & $\mathrm{X}$ & $1 / 2$ \\
Customer & $1 / 2$ & 1 & 2 & $\mathrm{x}$ \\
\hline
\end{tabular}


Table 6. Cluster pairwise comparisons with respect to perspectives.

\begin{tabular}{|c|c|c|c|c|c|c|c|}
\hline $\begin{array}{c}\text { With Respect to } \\
\text { Financial } \\
\end{array}$ & Financial & $\begin{array}{c}\text { Learning and } \\
\text { Growth } \\
\end{array}$ & Customer & $\begin{array}{c}\text { With Respect to Internal } \\
\text { Business Processes } \\
\end{array}$ & Financial & $\begin{array}{c}\text { Learning } \\
\text { and Growth }\end{array}$ & Customer \\
\hline Financial & $\mathrm{x}$ & 2 & 3 & Financial & $\mathrm{x}$ & $1 / 2$ & 2 \\
\hline $\begin{array}{l}\text { Learning and } \\
\text { Growth }\end{array}$ & $1 / 2$ & $\mathrm{x}$ & 2 & Learning and Growth & 2 & $\mathrm{x}$ & 3 \\
\hline Customer & $1 / 3$ & $1 / 2$ & $\mathrm{x}$ & Customer & $1 / 2$ & $1 / 3$ & $\mathrm{x}$ \\
\hline $\begin{array}{c}\text { With Respect to } \\
\text { Customer }\end{array}$ & Financial & $\begin{array}{c}\text { Internal Business } \\
\text { Processes } \\
\end{array}$ & $\begin{array}{c}\text { Learning and } \\
\text { Growth }\end{array}$ & Customer & & & \\
\hline Financial & $\mathrm{x}$ & $1 / 2$ & 1 & $1 / 3$ & & & \\
\hline $\begin{array}{l}\text { Internal Business } \\
\text { Processes }\end{array}$ & 2 & $\mathrm{x}$ & 2 & $1 / 2$ & & & \\
\hline $\begin{array}{l}\text { Learning and } \\
\text { Growth }\end{array}$ & 1 & $1 / 2$ & $\mathrm{x}$ & $1 / 3$ & & & \\
\hline Customer & 3 & 2 & 3 & $\mathrm{x}$ & & & \\
\hline
\end{tabular}

Table 7. Node pairwise comparisons with respect to green transport strategy.

\begin{tabular}{ccccccccc}
\hline In Financial & F1 & F2 & In Learning and Growth & L1 & L2 & In Customer & C1 & C2 \\
\hline F1 & $\mathrm{x}$ & $1 / 2$ & $\mathrm{~L} 1$ & $\mathrm{x}$ & $1 / 3$ & $\mathrm{C} 1$ & 2 & $\mathrm{x}$ \\
$\mathrm{F} 2$ & 2 & $\mathrm{x}$ & $\mathrm{L} 2$ & 3 & $\mathrm{x}$ & $\mathrm{C} 2$ & $\mathrm{x}$ & $1 / 2$ \\
\hline
\end{tabular}

Table 8. Node pairwise comparisons with respect to measures.

\begin{tabular}{|c|c|c|c|c|c|c|c|c|}
\hline $\begin{array}{l}\text { With F1 in } \\
\text { Learning and Growth }\end{array}$ & L1 & $\mathbf{L 2}$ & $\begin{array}{l}\text { With F2 in } \\
\text { Learning and Growth }\end{array}$ & L1 & $\mathbf{L 2}$ & $\begin{array}{l}\text { With P1 in } \\
\text { Learning and Growth }\end{array}$ & $\mathbf{L 1}$ & $\mathbf{L 2}$ \\
\hline L1 & $\mathrm{x}$ & $1 / 2$ & L1 & $\mathrm{x}$ & $1 / 3$ & $\mathrm{~L} 1$ & $x$ & $1 / 2$ \\
\hline $\mathrm{L} 2$ & 2 & $\mathrm{x}$ & $\mathrm{L} 2$ & 3 & $\mathrm{x}$ & L2 & 2 & $\mathrm{x}$ \\
\hline $\begin{array}{c}\text { With C2 in Learning } \\
\text { and Growth }\end{array}$ & $\mathbf{L 1}$ & $\mathbf{L 2}$ & With $\mathrm{C} 2$ in Financial & F1 & F2 & With P1 in Financial & F1 & F2 \\
\hline L1 & $\mathrm{x}$ & $1 / 2$ & $\mathrm{~F} 1$ & $\mathrm{x}$ & 2 & $\mathrm{~F} 1$ & $x$ & 1 \\
\hline $\mathrm{L} 2$ & 2 & $\mathrm{x}$ & $\mathrm{F} 2$ & $1 / 2$ & $\mathrm{x}$ & $\mathrm{F} 2$ & 1 & $\mathrm{x}$ \\
\hline
\end{tabular}

Global weights of the measures obtained using the SuperDecisions software are shown in Table 9 in the "Normalized by Goal" column. The most significant measures are L2: Increasing the green innovativeness of the logistics staff (32\%) and F1: Transport cost saving (17\%). These measures are followed by $\mathrm{C} 2$ : Reducing the local environmental impacts (16\%), L1: Increasing the green knowledge (15\%), and P1 Decreasing the $\mathrm{CO}_{2}$ emissions (14\%). The lowest priority obtained measure $\mathrm{C} 1$ : Increasing the green image of transport because it doesn't contribute to the decrease of any negative environmental impacts of the company transport.

The significance of the L2 measure is given by the fact that the measure affects positively all other perspectives and measures. The successful implementation of GT strategy in the long term run always depends on high skilled and innovative logistics staff. The significance of the F1 measure corresponds to the Ideal GT strategy, which prefers such green initiatives that are related to low costs or better to cost savings. These two measures should be incorporated into the company BSC model to ensure the unity between the company strategy and the GT strategy. 
Table 9. Global weights of the measures.

\begin{tabular}{ccc}
\hline Measure & Normalized by Cluster & Normalized by Goal \\
\hline F1 & 0.72244 & 0.16896 \\
F2 & 0.27756 & 0.06491 \\
P1 & 1.00000 & 0.14180 \\
L1 & 0.32562 & 0.15240 \\
L2 & 0.67438 & 0.31563 \\
C1 & 0.00000 & 0.00000 \\
C2 & 1.00000 & 0.15630 \\
\hline
\end{tabular}

\subsubsection{Evaluation of Green Transport Strategy Reaching}

The main result of the evaluation step using the SuperDecisions software is shown in Table 10. The present state of reaching the green objectives and GT strategy is $80 \%$.

Table 10. Evaluation of the GT strategy reaching.

\begin{tabular}{cc}
\hline Alternatives & Values \\
\hline Thresholds & 0.21466 \\
Realities & 0.79884 \\
Targets & 1.00000 \\
\hline
\end{tabular}

Thanks to the overall threshold value, the inclusion of the calculated real value into the pre-defined categories can be done. A value less than the overall threshold value means the GT strategy is implemented in an unacceptable way. On the contrary, a value that is greater than the overall target value means excellent GT strategy reaching. The interval between the overall target and threshold values can be divided into three categories (see Table 11). Suitable correction initiatives must be prepared for each category.

Table 11. System for evaluation of the GT strategy reaching.

\begin{tabular}{ccc}
\hline Category & Interval & Corrections \\
\hline Excellent & $>1.00$ & Unneeded \\
Very good & $0.73-1.00$ & Small \\
Good & $0.47-0.73$ & Large \\
Bad & $0.21-0.47$ & Principal change of GT strategy \\
Unacceptable & $<0.21$ & Total change of GT strategy \\
\hline
\end{tabular}

The present state of the evaluated GT strategy implementation is very good that is why only small correction initiatives must be planned and realized.

\section{Results and Discussion}

The presented case study has demonstrated the viability of the conceptual framework for creating the Green Transport Balanced Scorecard models from the viewpoint of industrial companies and supply chains. The framework is able to build GTBSC models, which allow both GT performance evaluation and support an effective implementation of GT strategies. 
Using the ANP method is crucial for this conceptual framework. If a multi-criteria decision making method that requires independence among measures were to be used, the results would be very different. To verify this fact, the Analytic Hierarchy Process (AHP) also developed by Saaty [37,38] was applied. The AHP is a special type of the ANP, thus the SuperDecisions software could be used again for the prioritization of GTBSC measures. In this case, only pairwise comparison matrices from Tables 5 and 7 were taken into consideration. The comparison of the obtained results using the two multi-criteria decision making methods is presented in Table 12. From the table, it is obvious that the most significant L2 measure obtained only the weight of 9\%. The reason is that the AHP method isn't able to take interdependencies among the L2 measure and other measures into consideration. From Figure 5 and Table 2, it is evident that L2 Increasing the green innovativeness of logistics staff has a positive impact on measures F1, F2, P1, and C2. Thanks to this fact, the L2 must be the most significant measure. Similarly, it is possible to explain the others' differences among the calculated weights.

Table 12. Comparison of results using analytic network process (ANP) and analytic hierarchy process (AHP) methods.

\begin{tabular}{ccc}
\hline Measure & ANP Weights & AHP Weights \\
\hline F1 & 0.17 & 0.14 \\
F2 & 0.06 & 0.28 \\
P1 & 0.14 & 0.23 \\
L1 & 0.15 & 0.03 \\
L2 & 0.32 & 0.09 \\
C1 & 0.00 & 0.15 \\
C2 & 0.16 & 0.08 \\
\hline
\end{tabular}

Provided the AHP global weights would be used for evaluation of reaching the selected GT strategy, the present state of achieving the green objectives and GT strategy would be only $73 \%$ (see Table 13), i.e., only good.

Table 13. Evaluation of the GT strategy reaching using the AHP method.

\begin{tabular}{cc}
\hline Alternatives & Values \\
\hline Thresholds & 0.25333 \\
Realities & 0.73471 \\
Targets & 1.00000 \\
\hline
\end{tabular}

In practical utilization of the designed conceptual framework, two problems occur very often:

(1) The ANP methodology is relatively time consuming and difficult to use. It will be a problem for small and medium companies. Thus, the conceptual framework is suitable, rather, for large companies, which use team and project work in strategic decision making processes as a company standard and can invite external ANP experts to support the methodology.

(2) The second problem is to find such measure(s) to describe correctly the achieving objective. Judgment evaluation can be a possible solution in these cases. Since the evaluation is usually vague, the authors' future works will be oriented on utilisation of the Fuzzy Analytic Network Process (FANP) method in the designed conceptual framework. 


\section{Acknowledgments}

This work was supported by the project of the SKODA AUTO University Internal Grant Agency No. SIGA/2014/01.

\section{Author Contributions}

David Staš prepared the literature review from the area of the Balanced Scorecard model, participated in the conceptual framework design, the case study preparation and discussion of the obtained results. Radim Lenort participated in the conceptual framework design, the case study preparation and discussion of the obtained results. Pavel Wicher prepared the literature review from the area of Analytic Network Process method, conducted all calculations using the SuperDecisions software and participated in the analysis and discussion of the obtained results. David Holman prepared the literature review from the area of green transport evaluation systems, participated in the case study preparation and discussion of the obtained results. All authors have read and approved the final manuscript.

\section{Conflicts of Interest}

The authors declare no conflict of interest.

\section{References}

1. United Nations Department of Economic and Social Affairs (UNDESA. Guide Book to the Green Economy. Available online: https://sustainabledevelopment.un.org/content/documents/ GE\%20Guidebook.pdf (accessed on 1 August 2015).

2. United Nations Environment Programme (UNEP). Measuring Progress towards a Green Economy. Available online: http://www.unep.org/greeneconomy/Portals/88/documents/research_ products/MeasuringProgress.pdf (accessed on 1 August 2015).

3. Pojani, D.; Stead, D. Sustainable Urban Transport in the Developing World: Beyond Megacities. Sustainability 2015, 7, 7784-7805.

4. Hu, R. Sustainable Development Strategy for the Global City: A Case Study of Sydney. Sustainability 2015, 7, 4549-4563.

5. Jeon, C.M.; Amekudzi, A.A.; Guensler, R.L. Sustainability assessment at the transportation planning level: Performance measures and indexes. Transp. Policy 2013, 25, 10-21.

6. Texas Transportation Institute: Developing Sustainable Transportation Performance Measures for TxDOT'S Strategic Plan-Technical Report. Available online: http://ti.tamu.edu/documents/ 0-5541-1.pdf (accessed on 1 August 2015).

7. York Region: Moving on Sustainability: Transportation Master Plan Update. Available online: https://www.york.ca/wps/wcm/connect/yorkpublic/c8653c2f-b796-449c-b39e-e2b9bb2e4b8f/ TMPU_Executive_Summary_Nov2009.pdf?MOD=AJPERES (accessed on 1 August 2015).

8. Super Green Supporting EU's Freight Transport Logistics Action Plan on Green, Green Corridors Handbook. Available online: http://www.weastflows.eu/media//Supergreen-Project-brief_1.0.pdf (accessed on 1 August 2015). 
9. Litman, T. Developing Indicators for Comprehensive and Sustainable Transport Planning. TRB 2007, 2017, 10-15.

10. Kurien, G.P.; Qureshi, M.N. Performance Measurement Systems for Green Supply Chains Using Modified Balanced Score Card and Analytical Hierarchical Process. Sci. Res. Essays 2012, 7 , 3149-3161.

11. Yanxiang, P. Construction of Green Supply Chain Performance Evaluation System Based on the Balanced Scorecard. Adv. Inf. Sci. Serv. Sci. (AISS) 2013, 5, 655-662.

12. European Economic Area (EEA). Are We Moving in the Right Direction? Indicators on Transport and Environment Integration in the EU. Available online: http://www.eea.europa.eu/publications/ ENVISSUENo12 (accessed on 1 August 2015).

13. Brožová, H.; Růžička, M. The AHP and ANP models for transport environmental impacts assessment. WSEAS Trans. Power Syst. 2010, 5, 233-242.

14. Kaplan, R.S.; Norton, D.P. The Balanced Scorecard-Measures That Drive Performance. Harv. Bus. Rev. 1992, 70, 71-79.

15. Saaty, T.L.; Vargas, L.G. Decision Making with the Analytic Network Process: Economic, Political, Social and Technological Applications with Benefits, Opportunities, Costs and Risks; Springer: New York, NY, USA, 2013.

16. Staš, D.; Lenort, R.; Wicher, P.; Holman, D. Implementing the Green Transport Strategy using Balanced Scorecard and Analytic Network Process. In Proceedings of the 19th International Conference on Computers (part of CSCC'15), Zakynthos Island, Greece, 16-20 July 2015.

17. Kaplan, R.S.; Norton, D.P. Linking the Balanced Scorecard to Strategy. Calif. Manag. Rev. 1996, 39, 53-79.

18. Wang, Y.G.; Li, Y.-M.; Jan, C.-L.; Chang, K.-W. Evaluating firm performance with balanced scorecard and data envelopment analysis. WSEAS Trans. Bus. Econ. 2013, 10, 24-39.

19. Niven, P.R. IT Performance Management Using the Balanced Scorecard. In CIO Best Practices: Enabling Strategic Value with Information Technology; Stenzel, J., Ed.; John Wiley \& Sons: Hoboken, NJ, USA, 2007; pp. 185-221.

20. Olve, N.G.; Sjöstrand, A. Balanced Scorecard; John Wiley \& Sons: Chichester, UK, 2006.

21. Kaplan, R.S.; Norton, D.P. Using the Balanced Scorecard as a Strategic Management System. Harv. Bus. Rev. 1996, 74, 75-85.

22. Super Decisions Software. Available online: http://www.superdecisions.com/super-decisions-anintroduction/ (accessed on 1 August 2015).

23. Saaty, T.L. Fundamentals of the analytic network process-Multiple networks with benefits, costs, opportunities and risks. J. Syst. Sci. Syst. Eng. 2004, 13, 348-379.

24. Saaty, T.L. Fundamentals of the analytic network process-Dependence and feedback in decision-making with a single network. J. Syst. Sci. Syst. Eng. 2004, 13, 129-157.

25. Wolfslehner, B.; Vacik, H.; Lexer, M.J. Application of the analytic network process in multi-criteria analysis of sustainable forest management. For. Ecol. Manag. 2005, 207, 157-170.

26. Butler, J.B.; Henderson, S.C.; Raiborn, C. Sustainability and the Balanced Scorecard: Integrating Green Measures into Business Reporting. Manag. Account. Q. 2011, 12, 1-10. 
27. OIKOS: Towards a Sustainability Balanced Scorecard. Available online: http://backup.oikosinternational.org/fileadmin/oikos-international/international/Summer_Academies_old_ones_/ edition_2001/Papers/Paper_Bieker_Gminder.pdf (accessed on 1 August 2015).

28. Epstein, M.J.; Wisner, P.S. Good Neighbors: Implementing Social and Environmental Strategies with the BSC. Available online: http://www.greenprof.org/wp-content/uploads/2010/02/ Sustainability-BSC.pdf (accessed on 1 August 2015).

29. Hsu, C.W.; Hu, A.H.; Chiou, C.Y.; Chen, T.C. Using the FDM and ANP to Construct a Sustainability Balanced Scorecard for the Semiconductor Industry. Expert Syst. Appl. 2011, 38, 12891-12899.

30. Staš, D.; Lenort, R.; Wicher, P.; Holman, D. Conceptual Framework for Assessing the Green Transport Level in Industrial Companies and Supply Chains. Appl. Mech. Mater. 2015, 708, 87-92.

31. CLECAT: Logistics Best Practice Guide. Available online: http://www.clecat.org/ongoing-projects/ logistics-best-practice-guide.html (accessed on 1 August 2015).

32. 4flow. Costs and Benefits of Green Logistics. Available online: http://www.4flow.de/fileadmin/ user_upload/Unternehmen/Logistikforschung/4flow_supply_chain_management_study_2013_-_ abbreviated_version.pdf (accessed on 1 August 2015).

33. British International Freight Association: Environmental Case Studies-Examples of Good Practice the Freight Forwarding Sector. Available online: http://www.bifa.org/_Attachments/ Resources/1665_S4.pdf (accessed on 1 August 2015).

34. Electronic Court Records (ECR). ECR Sustainable Transport Project-Case Studies. Available online: http://ecr-all.org/files/Combined-Case-studies-_v1-8_220508_pro.pdf (accessed on 1 August 2015).

35. IRU. Report on Road Transport—Best Industry Practices. Available online: http://www.iru.org/ en_bookshop_item?_rewrite_sticky=bookshop-display-action\&id=10 (accessed on 1 August 2015).

36. IRU. Second Report on Road Transport-Best Industry Practices. Available online: https://www. iru.org/cms-filesystem-action?file=en_Publications/bip04.E.pdf (accessed on 1 August 2015).

37. Saaty, T.L. Decision making - The analytic hierarchy and network processes (AHP/ANP). J. Syst. Sci. Syst. Eng. 2004, 13, 1-35.

38. Saaty, T.L. Making and validating complex decisions with the AHP/ANP. J. Syst. Sci. Syst. Eng. 2005, 14, 1-36.

(C) 2015 by the authors; licensee MDPI, Basel, Switzerland. This article is an open access article distributed under the terms and conditions of the Creative Commons Attribution license (http://creativecommons.org/licenses/by/4.0/). 